\section{Referencialidad, funcionamiento y simbolismo ideológico del Norte y del Sur en A Better Life y Africa Paradis}

Referentiality, functioning and ideological symbolism of North and South in A Better Life and Africa Paradis

Georges Moukouti Onguédou; Anicet Christian Donfack Sounna

\section{RESUMEN}

En este artículo, consideramos que la configuración geopolítica del mundo viene determinada por nuevos paradigmas en las relaciones Norte-Sur. Cuestionamos la manera cómo se construyen el Norte y el Sur en A Better Life de Chris Weitz y Africa Paradis de Sylvestre Amoussou. Este cuestionamiento nos permite resaltar significados simbólicos e ideológicos de estos dos relatos fílmicos de inmigración contemporánea. Apoyándonos en las aportaciones teóricas de Henri Mitterand y Jacques Soubeyroux sobre el análisis del espacio, organizamos nuestro análisis en tres etapas. Después de realizar una topografía mimética de los relatos, enfocamos, en segundo lugar, la atención en el Norte y el Sur como espacios diegéticos para destacar sus significados en relación con las acciones de los sujetos migrantes. Luego, analizamos el simbolismo ideológico de los mismos espacios, determinando los factores que mandan esta polarización. Concluimos que ya no impera la lógica geográfica de los puntos cardinales en esta polarización norte-sur, sino y sobre todo la lógica hegemónica.

Palabras clave: Dialéctica; Norte-Sur; Relatos fílmicos; inmigración contemporánea; Simbolismo ideológico; Lógica hegemónica

\section{ABSTRACT}

In this paper, we consider that the world's geopolitical configuration is actually determined by a new paradigm in the relationship between North and South. We are questioning the way North and South are built as macro-spaces in Chris Weitz's A Better Life and Sylvestre Amoussou's Africa Paradis. This questioning process permits us to analyze the symbolical and ideological meanings of both films on contemporary migration. Based on the theoretical approach established by Henri Mitterand and Jacques Soubeyroux, we organize this analytical process in three steps. After realizing a mimetic topography, we pay attention to the functioning of North and South as diegetic spaces, in order to highlight their signification in relation to the trajectory of migrant characters. The third step deals with the analysis of the ideological symbolism of spaces, determining the factors that rule that polarization. We conclude that nowadays, the north/south polarization does not obey anymore to the geographical logic of cardinal point, but and much more to a logic of hegemony.

Keywords: dialectic; North-South; film tale; contemporary immigration; ideological symbolism; Hegemonic logic

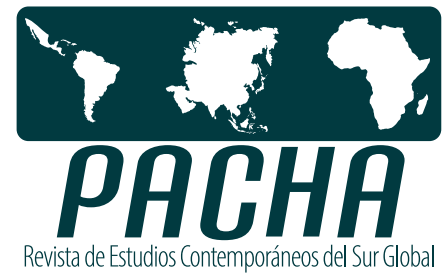

INFORMACIÓN:

https://doi.org/10.46652/pacha.v2i6.74

ISSN 2697-3677

Vol. 2, No. 6, 2021. e21074

Quito, Ecuador

Enviado: agosto 12, 2021

Aceptado: noviembre 14, 2021

Publicado: diciembre 04, 2021

Sección Dossier | Peer Reviewed

Publicación continua

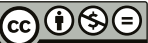

\section{open $\bigcirc$ Access}

\section{AUTORES:}

Georges Moukouti Onguédou Universidad de Maroua - Camerún moukouti@yahoo.fr

Anicet Christian Donfack Sounna Universidad de Maroua - Camerún a.donfack@yahoo.fr

\section{CONFLICTO DE INTERESES}

Los autores declaran que no existe conflicto de interés posible. FINANCIAMIENTO

No existió asistencia financiera de partes externas al presente artículo. NOTA

$N / A$
ENTIDAD EDITORA 


\section{Introducción}

Si partimos del mito bíblico de la creación del mundo, cuando Dios expulsa del paraíso a Adán y Eva y que estos últimos deben buscarse nuevas tierras donde morar, entonces podemos entender que migrar está en el imaginario de todos los humanos desde épocas remotas. Las creaciones artísticas, especialmente la literatura y el cine, vienen abordando el fenómeno migratorio humano como algo natural, voluntario o impuesto por múltiples circunstancias, desde la búsqueda de mejores condiciones de vida, de mejores tierras y hasta por catástrofes naturales o sanitarias (peste, gripe, Covid-19, etc.), discriminación u opresión, etc. Con el presente artículo, nos interesamos a la representación de la dialéctica Norte-Sur en dos películas sobre inmigración contemporánea. Del enfrentamiento Norte-Sur, confrontamos representaciones tanto simbólicas como ideológicas de estos macroespacios en A Better Life de Chris Weitz y Africa Paradis de Sylvestre Amoussou; dos textos que confrontan precisamente paradigmas en cuanto a la representación de ambos espacios.

EnABetter Life (2011), el estadounidense Chris Weitz recoge algunos días de la vida de un inmigrante mexicano ilegal en Estados Unidos, en la ciudad de Los Ángeles. Carlos Galindo, como otros inmigrantes hispanoamericanos atrapados en las garras de una sociedad capitalista y antipática, lucha por ofrecerle a su único hijo una oportunidad de tener una vida mejor que la que tenían en México. Enfrentando dos situaciones socioeconómicas dispares (escaseces, por una parte y abundancias, por otra), el cineasta logra confrontar el Sur (México y, por extensión, los países latinoamericanos de donde proceden los inmigrantes) con el Norte (Estados Unidos, lugar de ensueño para dichos inmigrantes).

En Africa Paradis (2007), el beninés Sylvestre Amoussou se apoya en el artífice posibilitado por el recurso a la Ucronía para invertir la trayectoria migratoria y las funciones simbólicas del Norte y del Sur. Nos proyecta en un África que, entrado el año 2033, ya es próspera. En el mismo momento, Europa ha decaído política, económica y culturalmente. Desde luego, miles de inmigrantes europeos entre los cuales la pareja protagonista Olivier Morel y Pauline huyen de la guerra, la violencia y la precariedad e inmigran en África, el nuevo paraíso, en busca de mejores condiciones de vida. Se trata de una reconfiguración y una redistribución de los roles y responsabilidades de los actores implicados en los flujos migratorios; reconfiguración y redistribución tributarias de los cambios que está conociendo el mundo en la actualidad. Consideramos esta visión del mundo sobre la inmigración al revés, es decir, norteños que emigran hacia países sureños, para confrontarla con la visión occidentalizada del fenómeno, dejando constancia de la carga simbólica e ideológica del Norte y del Sur en cada relato.

Si durante muchos años el espacio ha ido separado y sometido a la noción de tiempo y puesto como un mero soporte de la acción, en la actualidad, nadie puede poner en duda el alto valor que tiene la coordenada Espacio en la estructuración del universo del relato. Al enunciar su definición de la novela, Forster (1983, p.71) subraya que es "un relato en prosa en el que alguien cuenta lo que sucede a unos personajes, en ciertos momentos y en determinados lugares". Esta definición tiene el mérito de destacar el papel preponderante del espacio en la configuración de todo universo narrativo ya que la percepción que el hombre tiene del mundo, la proyección que hace de sus experiencias y sus observaciones se lleva a cabo a través de las dimensiones o de los objetos del espacio. Así, “el espacio - como añade Garrido Domínguez (1996, p. 210) - es mucho más que el mero soporte o el punto de referencia de la acción: es su auténtico propulsor". De igual manera, Henri Lefèbvre (1974, p. 155) observa que "tout langage se situe dans un espace", que "tout discours dit quelque chose sur un espace" y que "tout discours parle d'un espace". 
Considerado aisladamente, el espacio carece de significado y resulta una unidad neutra. Así, "sólo cuando se le dota de personajes y acciones toma significado y, a partir de entonces, puede incluso condicionar el desarrollo de la fábula, superando su cometido básico de servir como escenario de la acción para convertirse en agente de la historia" (De Juan Ginés, 2004, p. 22), y una clave de análisis imprescindible, de acuerdo con Philippe Hamon (1993, p. 108).

Como hipótesis fundamentales, planteamos que el espacio, al igual que las demás categorías del relato, participa en la coherencia del tejido narrativo y que el análisis de su funcionamiento y sus interacciones con las demás categorías textuales puede permitir llegar a las estructuras profundas del texto. Para asegurar la coherencia de nuestros análisis, optamos por una metodología desarrollada en tres niveles por Jacques Soubeyroux (2003, p. 28) quien se apoya en los aportes teóricos de Henri Mitterrand (1980) y Philippe Hamon (1981):

- Un nivel referencial, que será más o menos mimético según los textos, pero que no puede menos de existir, porque no se puede imaginar un texto narrativo sin referencia alguna al mundo real;

- Un nivel diegético que definirá las reglas de funcionamiento de las coordenadas espaciales dentro del universo narrativo, en su relación con las demás categorías novelescas (tiempo, narración y personajes)

- Un nivel simbólico, que consideramos como propio de la ficción y que determina la significación profunda del texto.

\section{El norte y el sur: nivel referencial}

Varios teóricos concuerdan sobre el hecho de que la distribución de los espacios en un relato no solo sirve para dotar éste de una geografía, sino también sirve para crear una ilusión de realidad (Roland Barthes, 1968; Milagros Esquerro, 1985). Ningún detalle parece gratuito y, desde entonces, corroboramos las explicaciones de Henri Mitterand quien afirma que "c'est le lieu qui fonde le récit, parce que l'évènement a besoin d'un ubi autant que d'un quid ou d'un quando; c'est le lieu qui donne à la fiction l'apparence de la vérité" (1980, p. 194). En esta primera fase de nuestro análisis, considerando los límites que nos impone un artículo, vamos a inventariar los espacios narrativos en las dos películas. Insistimos en aquellos que se revelan de una máxima importancia en la trayectoria de los sujetos migrantes.

En A Better Life, toda la trama tiene como marco el espacio estadounidense. El espacio del Sur solo se puede construir en la imaginación del espectador. El protagonista Carlos Galindo es un inmigrante mexicano que trabaja en Estados Unidos desde unos diez años. Procede del Sur aquí representado por México donde habría llevado una vida difícil antes de cruzar el peligroso espacio del desierto fronterizo (que aparece al final de la película) tras contratar los servicios de un coyote y superar todos los obstáculos establecidos por la migra. Al revés, los espacios al Norte son más explícitos. Entre ellos destacan esencialmente la casa de Garlindo, las calles, Aguadulce, las mansiones, la escuela, etc.

La casa de Carlos Galindo está situada en uno de los barrios de Los Ángeles; barrios denominados dormitorios. Este local con humildes dimensiones alberga a la familia Galindo. El salón desempeña a la vez el papel de cuarto de dormir para el padre por la tarde cuando éste vuelve del trabajo. En el patio trasero de la casa, hay un jardín en el cual Carlos tiene preparadas las semillas de flores y otros árboles para decorar mansiones. Las calles en esta película no vienen nombradas. 
Son espacios públicos en los que transitan poblaciones, coches, inmigrantes legales e ilegales. Son sobre todo espacios de frustración para inmigrantes ilegales de la clase de Carlos Galindo. Estos inmigrantes tienen que disfrazarse cada vez que cruzan las calles a causa de las recurrentes patrullas policiales. Aguadulce es el nombre irónico utilizado para designar el establecimiento penitenciario reservado para criminales y sobre todo para inmigrantes ilegales que cometen delitos "graves" (como moverse sin documentación legal). Este establecimiento penitenciario es muy grande, y su construcción es muy típica de modelos estadounidenses, con muchas secciones, incluyendo despachos, una gran sala de estar para todos los prisioneros, una sala para las visitas, un campo de juegos, etc. En este lugar será detenido Carlos Galindo después de ser cogido por la policía. Aquí recibirá visitas de su hermanita y de su abogado. Este último le informará sobre las duras leyes establecidas contra los inmigrantes ilegales en Estados Unidos.

Además de estos espacios, hay otros que albergan acciones en la película, como las mansiones de la ciudad de Los Ángeles, la escuela donde estudia el hijo del protagonista, el despacho de los agentes de seguridad del instituto, las esquinas de las calles donde se agrupan los inmigrantes en busca de trabajo, las tiendas de recuerdo, la casa de la familia de Celo, el alojamiento comunitario para inmigrantes ilegales donde viven los inmigrantes al margen de la sociedad y sus leyes, el campo del congreso nacional Charro, el restaurante, el garaje "Patriot auto mart” y el jardín familiar de la familia Galindo.

En la película Africa Paradis los diferentes espacios presentados ante el objetivo de la cámara son muy representativos del trayecto seguido por los inmigrantes del Norte hacia el Sur. La acción descrita en la película del beninés empieza con la descripción de la decadencia que caracteriza el macroespacio del antiguo Norte (Europa), preso de guerras, dictaduras, movimientos revolucionarios violentos, hambre y epidemias de todo tipo. En el año 2033, momento en que se desarrolla la historia de la película, Europa se presenta como un espacio completamente decadente. En la segunda secuencia de la película, una voz en off nos da la siguiente descripción del continente europeo que, aunque se refiera a algunos países, parece dar cuenta de la situación general:

L'unification ne s'étant pas faite, l'Europe est devenue un continent sous-développé. Des luttes sauvages opposent régulièrement des peuplades différentes: belges, suédoise, française, espagnole, hollandaise [...]. Les turcs ont pris le pouvoir en Allemagne, la Russie est gouvernée par un cartel de Gangster, le Vatican vit sous la dictature d'un pasteur protestant, l'Angleterre est devenue une colonie du Guatemala, et la France, la France est tombée dans une totale décadence.

En este macro espacio destacan otros espacios narrativos como el consulado de los Estados Unidos de África, donde esperan largas filas de candidatos a la emigración hacia el continente africano. También destacan la estación de gasolina, la casa de Olivier y Pauline, el aeródromo y la costa de los Estados Unidos de África. La representación de los espacios al nuevo Norte (el continente africano) denota cierta opulencia y un grado de desarrollo muy avanzado del "continente negro". Desde el punto de vista topográfico, este macro espacio se denomina Federación de los Estados Unidos de África. Carece de topónimos mencionados explícitamente. Tampoco se alude a su capital. Es constituido a su vez por varios microespacios en los que los africanos y la población de inmigrantes europeos conviven en un ambiente particularmente conflictual. Entre estos microespacios están el Centro de tránsito donde se detienen a los inmigrantes ilegales, el parlamento de la Federación, la casa del diputado Modibo Kodossou, la ciudad blanca, la calle, la plaza de la unidad, la cárcel, el aeropuerto, etc. 
Como puede observarse, la conjunción de los espacios, además de dotar los relatos de una geografía, deja entrever las oposiciones entre sus diferentes valores. Philippe Hamon llama esta coordenada de la narración "un opérateur de lisibilité fondamentale" (1993, p. 108), a la vez una premonición y un signo de valores y relaciones muy diversas (Mieke Bal, 1990, pp. 50-52). El espacio es un signo del personaje y, en cuanto tal, "cumple un cometido excepcional en su caracterización, tanto en lo que se refiere a su ideología como a su mundo interior o personalidad, su comportamiento" (Bobes Naves, 1985, pp. 216-217). En la próxima fase de este análisis, enfocamos la atención en las funciones que desempeñan los diferentes espacios, según las acciones que en ellos tienen lugar. Se trata de la toposemia funcional.

\section{Toposemia funcional del Norte y del Sur}

El espacio adquiere un significado que va más allá de su carácter meramente descriptivo. Al respecto, Milagros Ezquerro (1983, p. 78) considera que "l'espace fictionnel n'est pas descriptif, mais plutôt allusif; il ne se donne pas à voir, il est le signe, c'est-à-dire qu'il signifie et qu'il désigne autre chose que lui-même". En sus relatos, los directores utilizan el espacio como un componente esencial que sostiene el desarrollo de la trama. Como explica Florence Paravy, los elementos espaciales "ont tous une valeur indicielle [...] concernant le personnage, dont ils révèlent le statut social, la psychologie et le rôle dramatique” (1999, p. 220). Por eso, interesa observar que en la organización de los diferentes ámbitos de actuación y, por lo tanto, del papel del espacio en las películas, ofrecen una representación de la realidad que no es totalizadora. Más bien, reparten la acción primero en macroespacios, luego en microespacios específicos, marcados por cierto número de oposiciones: público/privado, eufórico/disfórico, etc. Estas oposiciones se manifiestan al estudiar las diferentes semiotizaciones y los alcances simbólicos que adquieren los espacios.

\subsection{El Norte y el Sur como espacios eufóricos y/o de realización}

En la película A Better Life, el inmigrante Carlos Galindo ha abandonado su México natal (Sur) en busca de una mejor vida en Estados Unidos (Norte). Tiene la suerte de beneficiarse de la ayuda de uno de sus compadres mexicanos con quien colabora desde hace más de seis años. Logra trabajar en las mansiones de la ciudad de Los Ángeles, cuidando a diario los jardines. Desde luego, las mansiones se convierten en espacios de realización para él. Su ardor y su devoción le permiten ganarse la vida, asegurarse un alojamiento y velar en solitario por la educación de su hijo Luis, matriculado en un colegio público. Después de ganarse bastante dinero, se compra una camioneta que en la película simboliza el sueño americano realizado. Con esta nueva situación, se vuelve su propio patrón y puede contratar a su vez a inmigrantes para auxiliarle en sus pequeñas tareas cotidianas. La ciudad de Los Ángeles como espacio de realización se ve igualmente a través de la situación de otros inmigrantes, como Blasco, un mexicano que después de entrar ilegalmente en Estados Unidos, ha podido aprender un oficio y, con el paso de los años, se ha vuelto también su propio patrón.

En Africa Paradis, la trama se abre con un diaporama que presenta una sucesión de imágenes de una Europa (Sur) en decadencia, presa de la corrupción, los golpes de estado, las guerras intertribales e interestatales, la violencia y, como colmo de todos estos mayales, la miseria en todos los sectores de la vida en el viejo continente. En estas condiciones extremas que no pueden favorecer el desarrollo de la población, el viaje hacia el continente africano (Norte) se convierte en una meta que hay que alcanzar a toda costa. Así, Olivier Morel y Pauline forman parte de la horda de inmigrantes que, en el consulado de los Estados Unidos de África en Francia, se animan para tener un visado y, consiguientemente, un empleo que les permita tener una vida mejor que 
la que tienen en su patria. Rechazada su petición por rehusar los empleos disponibles para ellos, cruzan la frontera de manera ilegal. Este cruce, si bien parece ser una puerta de entrada hacia la felicidad, en esta película simboliza más bien la entrada en el infierno para Olivier Morel. Este se va a enfrentar con dificultades de todo tipo hasta su repatriación. Sin embargo, para Pauline, la vida cambia positivamente, porque es empleada como ama de casa en la residencia del señor Kodossou, diputado y presidente del Partido Liberal de la Unión Africana. Finalmente, ella se casa con él y África se convierte en su paraíso terrenal; de ahí, África como espacio eufórico y de realización.

La misma felicidad la conocen otros inmigrantes europeos que trabajan en la sociedad africana como chóferes, empleados en residencias y camareros. Como se puede constatar en las películas, el Norte como espacio permite en un primer momento al inmigrante realizarse, es decir, tener un empleo y vivir feliz. Sin embargo, parece existir una fuerza superior, una especie de espada de Damocles que vigila la conducta del inmigrante y le impide soñar con más de lo que tiene. Entonces, y paradójicamente, ser excesivamente ambicioso para un inmigrante puede tornar su vida en un infierno y el espacio del Norte pasa a funcionar como un espacio de opresión para el inmigrante, como lo vemos a continuación.

\subsection{El Norte y el Sur como espacios disfóricos o de inseguridad}

Al evocar el concepto de disforia, aludimos a una emoción desagradable o molestia (tristeza, depresión, ansiedad, inestabilidad o inquietud) que experimenta un personaje como consecuencia de su disyunción con un espacio en el que se encuentra. Así, se considerarán espacios disfóricos aquellos que ejercen repulsión sobre los sujetos migrantes. Son espacios que se asumen como lugares de derrota, opresión y encierro de los personajes.

En la película $A$ Better Life, hay una ausencia de informaciones sobre Carlos pero que puede completarse con lo que ocurre en Africa Paradis. En efecto, Carlos es un migrante que habría tenido que sufrir difíciles condiciones de vida; las cuales lo han obligado a marcharse de su país. Habría solicitado un visado para viajar; lo que le habría sido negado y habría tomado el camino del desierto, junto con otros sujetos migrantes hacia Los Ángeles y empezar una nueva vida. El Sur (México), debido a la escasez de posibilidades que ofrecía al sujeto migrante, se ha convertido en un lugar disfórico para él. Entonces, ha realizado el desplazamiento hacia el Norte (Estados Unidos) donde ha experimentado durante algunos años el éxito social y económico. Sin embargo, los pronósticos de un porvenir mejor no se han concretado y el protagonista se ha dado cuenta de que la frontera no es un mero obstáculo geográfico que hay que cruzar, sino que se desdobla y adopta otras formas, sobre todo simbólicas.

El sujeto migrante se da cuenta de que en realidad, su viaje no ha acabado, ya que se encuentra detenido y todos sus esfuerzos anulados, como si existiera una especie de proyección del estado de miseria de su México natal en los Estados Unidos. Al final de la película, es repatriado a México. Sin ninguna transición, en la escena siguiente a su repatriación, Carlos y otro grupo de migrantes intentan otra vez la aventura migratoria, prueba de que el sujeto no llega a hacer cuerpo con su país de origen y ve en la emigración la única vía de rescate. Desde esta perspectiva también, la película reproduce en cierta medida la estructura del mito de Sísifo donde el protagonista está condenado a volver a empezar eternamente una tarea que se salda por un fracaso.

En Africa Paradis, Sylvestre Amoussou devuelve al Occidente todos los peores clichés que se suelen aplicar a África. Europa (nuevo Sur) en esta ficción es descrita como un continente pobre y lleno de inquietudes. Esta pobreza se describe por la voz narradora en off. El Occidente cambia 
profundamente. Los valores de riqueza y desarrollo en todos los aspectos de la vida relacionados con este espacio quedan profundamente subvertidos gracias al artificio de la utopía que emplea el director del relato. Ahora, el antiguo Norte rima con violencia y hambre. Guerras civiles y hasta lingüísticas sacuden el continente europeo. Es la razón por la cual las poblaciones occidentales abandonan sus patrias para ir a África (nuevo Norte), la tierra de promisión, un lugar de paz y de felicidad. Se produce desde entonces una intensificación de los flujos migratorios, y la Federación de los Estados Unidos de África se ve obligada a reforzar el control de sus fronteras para frenar la llegada masiva de los inmigrantes que van modificando la configuración socioeconómica de este espacio. Esta situación acredita finalmente de una forma la tesis según la cual los artistas de los países en vía de desarrollo habrían tomado su revancha sobre la Historia, por medio del artificio de la Ucronía.

Algunos espacios públicos y privados alternan funcionalmente entre libertad y reclusión para los sujetos migrantes. En ambos relatos por ejemplo, los espacios privados desempeñan, además, el doble papel de lugares de reclusión y de seguridad para los inmigrantes. En A Better Life, el espacio de la calle actúa como una frontera para el protagonista Carlos Galindo, porque debido a su presencia ilegal en el territorio estadounidense, no puede moverse libremente. La misma situación se produce con los protagonistas inmigrantes de la película de Sylvestre Amoussou, que por su origen europeo y por haber entrado clandestinamente en África, no pueden moverse en toda libertad en la calle y en otros espacios públicos. Desde luego, porque los espacios públicos infunden miedo e inseguridad, los privados se cargan semánticamente de libertad, intimidad, sosiego y emulación para los inmigrantes. En A Better Life, la casa familiar de los Galindo es el espacio donde padre e hijo pueden encontrarse, charlar tranquilamente y descansar, lejos de todas las miradas amenazantes y desconfiadas.

En Africa Paradis, si bien es cierto que la mayoría de los espacios públicos de la Federación de los Estados Unidos de África oprimen a los inmigrantes europeos, los espacios privados aquí simbolizan la seguridad para los mismos. Así, la apretada sala que le sirve de habitación al chófer europeo de un ministro africano se vuelve un amparo provisional para Olivier Morel cuando éste está perseguido por la policía después de su evasión del centro de tránsito. De igual modo, la ciudad residencial de los inmigrantes europeos aparece como lugar de amparo, de regocijo, de ayuda mutua, de encuentro y de intercambio entre sí; poco importan sus nacionalidades. En esta residencia, por ejemplo, es donde Olivier Morel y los demás inmigrantes entablan relaciones; lo que le permite obtener un empleo como peón en la obra. En este mismo espacio será también desde donde los inmigrantes europeos organizarán la gran manifestación para el mejoramiento de sus derechos; una manifestación que degenerará en tragedia al final de la película.

\section{Simbolismo ideológico del Norte y del Sur}

Generalmente, desde el punto de vista de los estudios culturales, el término ideología "se refiere a aquellas imágenes, conceptos y premisas que proporcionan los marcos de pensamiento a través de los cuales representamos, interpretamos, entendemos y 'le damos sentido' a los aspectos de la existencia social” (Hall, 1981, p. 199). En otro texto y en similar dirección, el mismo Hall deja constancia de que "por ideología me refiero a los marcos mentales - los lenguajes, los conceptos, las categorías, la imaginería del pensamiento y los sistemas de representación - que las diferentes clases y grupos sociales utilizan para entender, definir, resolver y hacer entendible la manera en que funciona la sociedad" (Hall, 1981, p. 134). 
Las funciones espaciales analizadas anteriormente nos permiten en esta última etapa del análisis interpretar ideológicamente la representación de los espacios Norte y Sur en las películas del corpus. Se trata del simbolismo ideológico. Los valores de los espacios que oscilan entre euforia, disforia, libertad y reclusión y la circularidad del recorrido de los sujetos migrantes nos informan sobre las orientaciones ideológicas de los discursos de los directores de las películas. En palabras de Jean Claude Mbarga, en este nivel "se define los lugares de la acción en el texto, por la ocurrencia o la recurrencia de figuras arquetípicas del espacio con significaciones simbólicas que remiten a representaciones ideológicas más o menos conscientes” (2008, p. 102).

\subsection{La polarización Norte/Sur: ¿̇una cuestión de geografía o de poderío?}

Los motivos Norte y Sur aparecen, antes que nada, como espacios geográficos identificables en las películas. Esta división se da en los textos que analizamos a través de la conjunción de una serie de lugares identificables y presentados con características propias. El espacio narrativo como sistema abstracto evoca una realidad cognitiva y que el espectador quiere ver y experimentar. El lugar por su parte es el elemento que actualiza o hace perceptible al espacio. Germán Duarte que retoma a Gardies, nos ofrece una definición de los conceptos en estos términos:

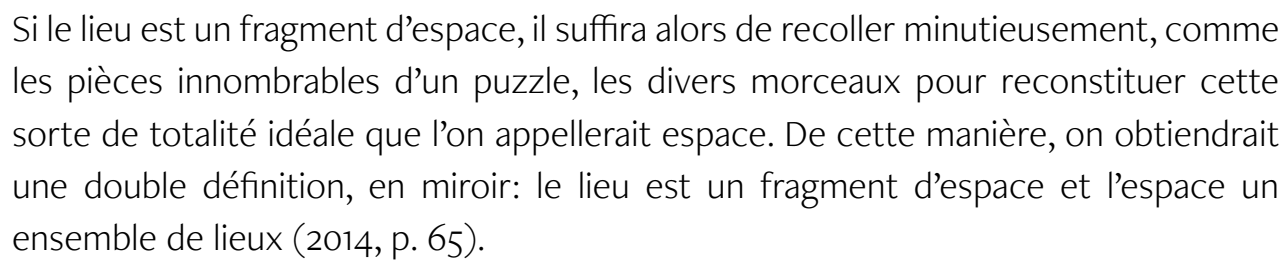

Como espacio geográfico, el norte aparece presentado explícitamente en la película $A$ Better Life donde connota la felicidad, las oportunidades y el sueño americano. Es simbolizado por la ciudad de Los Ángeles, donde vive y trabaja desde varios años el protagonista Carlos Galindo. Como señalábamos líneas arriba, en el cine, no se filma el espacio. Lo que hace la cámara es filmar objetos, paisajes, personajes que pueblan un espacio preciso: no se pueden filmar sino lugares (Gardies, 1993, p. 74). En la película de Chris Weitz, el Norte es representado a través de la descripción de lugares que permiten cartografiar el recorrido del inmigrante. Tenemos las mansiones de Los Ángeles donde trabaja, las calles y esquinas que funcionan como espacios públicos en los que se mueven y a veces se agrupan los inmigrantes en busca de empleo. A lo largo de las imágenes que desfilan en los diferentes travellings, se pueden identificar los mercados, las grandes avenidas y los barrios que permiten al espectador construir mentalmente el espacio del Norte y su organización.

En África Paradis de Sylvestre Amoussou, si bien el espacio del antiguo Norte es evocado en principio por una voz narradora en off que alude a la decadencia de las sociedades occidentales, en la secuencia número 3 de la película, el antiguo Norte es representado metafóricamente por la ciudad de París en Francia. En efecto, en esta secuencia, sirven de escenario para las acciones los lugares como el consulado de los E.U.A. donde acuden multitud de europeos que aspiran a tener un visado para el paraíso africano. También se puede observar una gasolinera que no funciona por falta de gasolina, la casa de Olivier Morel y Pauline presentada en un alumbramiento gris que denota miseria, tristeza y falta de oportunidades. 


\subsection{Simbolismo ideológico del Norte y del Sur en los relatos}

En los relatos de A Better Life y Africa Paradis, el espacio del Norte, que básicamente es un espacio relacionado con la opulencia, el desarrollo y las oportunidades, funciona como un espacio de alienación del inmigrante. Carlos Galindo en A Better Life, a pesar de haber cruzado la frontera física y haber ingresado en Estados Unidos, no ha logrado superar la frontera simbólica. El Norte reboza de espacios de opresión y alienación para el inmigrante. Los espacios públicos, y fundamentalmente las calles, casi siempre representan espacios de inseguridad y de alienación del inmigrante. Son síntomas de una sociedad donde impera la xenofobia y una retórica discursiva antiinmigrante. A través de los diferentes puntos del sistema espacial, destaca la hegemonía de una sociedad hipócrita cuyos medios de presión sobre las minorías de inmigrantes son denunciados en la obra.

Arrojados en espacios que en principio parecen eufóricos, se ven sometidos a la rutina de una vida sin esperanza y a veces sin posibilidad de éxito. Por ello, querer superar las estructuras de poder (volverse su propio patrón en A Better Life o la manifestación para el mejoramiento de los derechos de los inmigrantes en Africa Paradis) son empresas condenadas de antemano al fracaso. En otros términos, el Norte o el Sur, como lugares de destino de los inmigrantes son espacios que participan, no de la prosperidad del inmigrante en los relatos, sino que contribuyen a su exclusión, a su rechazo y a su desarraigo de toda referencia temporal y espacial. Si la repatriación del protagonista Carlos Galindo en A Better Life o también la de Olivier Morel en Africa Paradis son acontecimientos imprevistos y trágicos para las minorías de inmigrantes ilegales, no tienen bastante fuerza e importancia para sacudir a las superpotencias. Estos elementos acreditan por otra parte la compenetración Norte-Sur. Si el Sur remite al subdesarrollo, miseria, falta de oportunidades y alienación del personaje, la situación de marginación y exclusión de los inmigrantes parece justificar la idea según la cual el Norte contiene una parte del Sur. El significado del maniqueísmo Norte (centro) / Sur (periferia) sufre un desliz semántico, ya que las periferias subdesarrolladas ya no se encuentran más allá del Sur, sino precisamente tienden a acercarse cada día más a los centros poderosos y desarrollados.

La dinámica de las relaciones Norte-Sur hace que el Sur pueda aparecer como un Norte en potencia. En la película Africa Paradis, el director Sylvestre Amoussou intenta alcanzar este objetivo al dar a su relato un tinte afrofuturista por medio de la ucronía. Nos presenta otro mundo posible y otra Historia de la humanidad, donde el continente africano ha alcanzado su unificación y se encuentra en la cima del mundo. Ahora, el Occidente conoce la división, la dictadura, los conflictos civiles y militares, el hambre, la miseria y todo tipo de mayales que hacen de él un espacio de opresión y de repulsión para sus poblaciones. El director de la película recurre a la inversión de la Historia para crear un continente africano hiper-desarrollado. Este nuevo paraíso terrenal atrae a las poblaciones europeas. Al representar los espacios, enfoca más la atención en los factores internos (a los países de origen) y externos (a los países de destino) que motivan los desplazamientos de poblaciones.

En líneas generales, a pesar de utilizar métodos distintos, ambos directores de película formulan discursos críticos contra el Occidente, apuntando su ostracismo y su xenofobia con respecto al Otro. En A Better Life, el director Chris Weitz pone en tela de juicio la política migratoria estadounidense, con el excesivo control en las fronteras. A lo largo de la película, se observa el desenvolvimiento del jardinero que no busca sino una mejor opción de vida para su hijo. Sin embargo, parece que en su oficio, lo vigilan a diario, y él tiene que vivir a escondidas porque es un ilegal. Así, denuncia un sistema en el cual los inmigrantes son codiciados por ser una mano de obra barata para la construcción de los Estados Unidos, pero excluidos como seres 
humanos. No existe ninguna ley que asegure su protección o les garantice el mínimo de justicia. La voz del protagonista Carlos Galindo se vuelve, pues, la de millones de indocumentados. Su personaje representa una crítica a todos los políticos en Estados Unidos de América para quienes los inmigrantes indocumentados "son el nuevo enemigo" a la vez que adquieren notoriedad en tiempos de elecciones presidenciales para Demócratas y Republicanos.

El director Chris Weitz ha confesado su compromiso en una entrevista al afirmar que "they are eleven millions of immigrants, who make their possible for the country to grow. They are the victims of the political system in which it is easier for people to blame them than to understand and appreciate what they do for (my) country" (2011). Además, Julia Brookes, periodista de cine, con motivo de la ceremonia de los Oscars de los mejores actores concedida a Demián Bichir (Carlos Galindo) apunta:

\begin{abstract}
A Better Life is a political movie - although not of the earnest, tub-thumping kind. It's unavoidably political, because in cracking open the precarious, paradoxical world of an "illegal" immigrant in America today - and, by extension, the world of the millions of souls who among many other things pick our food, look after our kids, tend our gardens, and build our homes; people who are everywhere but invisible, indispensable but exploited, fearful but demonized, deeply rooted in the United States yet at risk at any moment of being ripped from their families and tossed out - the film can't help but show the life-shattering inhumanity and all-around bustedness of our immigration system, which was built by politics and which will, eventually, have to be unbuilt and rebuilt by politics.
\end{abstract}

Para esta periodista, Estados Unidos dispone finalmente de una política migratoria muy compleja y muy paradójica, que ora atrae a los inmigrantes, ora establece todo tipo de mecanismos para impedir su integración y libre desenvolvimiento en la sociedad angloamericana. El inmigrante ilegal vive bajo una estrecha y constante vigilancia, una situación poco confortable para quienes tratan de conservar su invisibilidad.

Sylvestre Amoussou en cuanto a él plantea el fenómeno migratorio, ya no como un fenómeno unilateral sino como uno global. A partir de su ficción, pone a Occidente entre los "tercermundistas" para que pueda reevaluar su aprehensión del fenómeno de la inmigración que siempre ha resultado de gran importancia para él. Denuncia la situación de los inmigrantes, así como todas las injusticias que sufren en las sociedades occidentales, porque el inmigrante siempre termina siendo considerado como el Otro peligroso para el Nosotros, independientemente del color de la piel. Por otra parte, replantea el dualismo clásico entre países industrializados y países en desarrollo, entre los llamados "primer" y "tercer" mundo, o entre centro y periferia, que se hace cada vez más difuso. El advenimiento de la globalización ha generado una multiplicidad de visiones sobre el desarrollo y promueve la disolución de antiguas unidades territoriales de tal manera que el "número de interdependencias transfronterizas aumenta, y Estados-naciones pierden su influencia sobre procesos económicos" (Müller-Mahn, 2009, p. 83). También, en contextos de pequeña escala, los procesos de desarrollo serían cada vez más heterogéneos. Desindustrialización, pobreza e inmigración causan el surgimiento de enclaves del "Sur" en medio de las metrópolis del "Norte", mientras que, en muchos países en desarrollo, los ricos se "encierran" en "islas de prosperidad", en sus condominios cerrados, protegiéndose de las masas pobres y de los inmigrantes. Por eso, "Norte" y "Sur" ya no son más claramente definibles como grandes bloques opuestos. "Norte” y "Sur" se compenetran, sin que se superen las contradicciones internas. 
Además, es de notar que las posiciones Norte y Sur no son estables, pues están sometidas a perpetuas mutaciones. Cuando las naciones del Sur consiguen cierto desarrollo económico, se convierten en "Norte", independientemente de su posición geográfica. La división se realiza principalmente a partir de factores económicos de los países. En otras palabras, el dualismo “Norte-Sur" responde a consideraciones de poderío y percepción y no de geografía. Dicho dualismo refleja la distribución de poder en el sistema internacional.

\section{Conclusiones}

En último análisis, el espacio narrativo aparece como un verdadero lugar de significación y nos ha permitido analizar la estructura profunda de los relatos del corpus y mostrar cómo las estructuras sociales e imaginarias se inscriben en el texto. Las dos películas parecen ilustrar las nuevas representaciones de los paradigmas Norte - Sur en las ficciones contemporáneas sobre inmigración. Los directores de las películas, al presentar un cuadro de los espacios y de las trayectorias de sujetos que abandonan sus tierras en busca de mejores condiciones de vida, nos arrojan en una interesante radiografía de las relaciones Norte-Sur y, al mismo tiempo, nos informan sobre las motivaciones de los flujos migratorios y sus consecuencias para los protagonistas involucrados en ellos. En la película A Better Life, Chris Weitz nos ofrece un retrato clásico de la representación de los motivos Norte y Sur, con un Norte (Estados Unidos) desarrollado y superpotente que aparece mucho más como una especie de vorágine en cuya garganta se ahogan los sueños de felicidad y prosperidad del inmigrante. El director denuncia las paradojas de la política migratoria de Estados Unidos al presentar la situación de un protagonista que, a pesar de vivir y trabajar en Estados Unidos desde muchos años, no hace más que vivir una felicidad quimérica, porque en realidad nunca ha superado las fronteras internas y simbólicas que lo colocan al margen de la sociedad en la que aspira vivir. Defiende la necesidad de una reforma de la política migratoria estadounidense que se destaca por sus paradojas. Real y paradójicamente, son los hombres políticos que más se benefician de la inmigración ilegal quienes condenan a los indocumentados. El director Chris Weitz critica el hecho de que los límites sirvan de ruptura en vez de puente y que el recelo contra el inmigrante crezca cada vez más, en un país que, difícilmente puede funcionar sin el brazo y el sudor de los inmigrantes.

En cambio, Sylvestre Amoussou, valiéndose del artificio de la Ucronía, nos ofrece una representación de la polarización Norte-Sur en las antípodas del modelo clásico. Por medio de su ficción utópica, subvierte los datos geopolíticos y económicos creando los Estados Unidos de África, un espacio de felicidad, de paz, de riqueza y de avance en casi todos los dominios. El Sur se convierte en un paraíso ansiado por las desesperadas poblaciones procedentes del antiguo Norte desgarrado por hambrunas, enfermedades, guerras y violencias. Al reescribir la historia, el director

africano reelabora el mapa del mundo y define otra alternativa en las relaciones Norte-Sur, en un tono irónico y hasta cómico. Este tono permite igualmente hacer una sátira de la hipocresía de las naciones europeas y sus políticas migratorias contradictorias que establecen todo tipo de barreras que dificultan la integración de los inmigrantes. Consecuentemente, y como habremos notado en los análisis, los postulados geográficos ya no bastan para determinar los paradigmas Norte-Sur; son entidades determinadas por una relación de hegemonía y de poderío. Es más, las fronteras entre las entidades Norte y Sur se vuelven cada vez más indefinidas y difusas, ya que actualmente, tienden a definirse por una lógica de desarrollo o de subdesarrollo. 


\section{Referencias}

Amoussou, S. (2007). Africa Paradis. [película]. Coproducción Benín-Francia; Metis Productions, Koffi Productions

Aumont, J., \& Marie, M. (2006). L'Analyse des films. Armand Colin.

Bal, M. (1995). Teoría de la narrativa (Una introducción a la Narratología). Cátedra.

Barthes, R. (1968). L'effet de réel. Communications 11. 84-89 https://doi.org/10.3406/comm.1968.1158

Bobes Naves, M. C. (1985). Teoría General de la Novela: Semiología de "La Regenta”. Gredos.

Brandt, W. (1980). North-South. A Program for Survival. The Report of the Independent Commission on International Development Issues under the Chairmanship of Willy Brandt. MIT Press.

Brookes, J. (2012, February 24). Oscars: How A Better Life's Chris Weitz and Demian Bichir Got Political. Rolling Stones. https://cutt.ly/bTZcXam

Casetti, F., \& Di Chio, F. (2003). Cómo analizar un film. Paidós.

De Juan Ginés, J. L. (2004). El espacio en la novela española contemporánea. (Tesis doctoral). Universidad Complutense de Madrid.

Ezquerro, M. (1983). Théorie et fiction. Le nouveau roman hispano-américain. CERS.

Forster, E. (1983). Aspectos de la novela. Debate.

García Canclini, N. (2002). La globalización imaginada. Paidós.

Gardies, A. (2014). Le récit filmique. Hachette.

Garrido Domínguez, A. (1996). El texto narrativo. Síntesis.

Hall, S. (1981). Sin garantías. Trayectorias y problemáticas en estudios culturales. Envión Editores-IEP- Instituto Pensar-Universidad Andina Simón Bolívar.

Hamon, P. (1981). Introduction à l'analyse du descriptif. Hachette.

Hamon, P. (1993). Du Descriptif. Hachette.

Lefèbvre, H. (1974). La production de l'espace. Anthropos.

Mbarga, J.-C. (1). El discurso de la novela sobre el espacio en Piso bajo, de Ramón Gómez de la Serna. Opción, 24(56). 92-105. https://produccioncientificaluz.org/index.php/opcion/article/view/6444

Mitterand, H. (1980). Le discours du roman. PUF.

Müller-Mahn, D. (2009). Disoluciones de la dicotomía "Norte-Sur: aspectos geográficos del debate sobre el desarrollo. Revista Mercator, 8(17), 7-23, http://www.mercator.ufc.br. /mercator /article /view/333

Paravy, F. (1999). L'espace dans le roman africain francophone contemporain. L'Harmattan.

Prensa Escenario (2012, enero 25). Entrevista Demian Bichir y Chris Weitz - A Better Life [video]. YouTube. https://youtu.be/wUHQwcko-dg

Soubeyroux, J. (1985). Pour une étude de l'espace dans le roman. CERS.

Soubeyroux, J. (2003). La representación del espacio en la narrativa española del siglo XX. Arbor, 176(693), 27-57. https://doi.org/10.3989/arbor.2003.i693.717

Weitz, C. (2011). A Better Life. [película]. Summit Entertainment. Lime Orchard Productions. 
PACHA 
PACHA 